\title{
Hand preference and developmental instability
}

\author{
RONALD A. YEO, STEVEN W. GANGESTAD, and WALTER F. DANIEL \\ University of New Mexico, Albuquerque, New Mexico
}

\begin{abstract}
The origins of individual variation in hand preference are unclear, with some theories emphasizing environmental factors, and others, genetic factors. In two studies, we investigated the hypothesis that developmental instability, leading to imprecise expression of a near-universal neural design, underlies phenotypic variation in hand preference and performance. In Study 1, a composite index of developmental instability was constructed from a checklist of minor physical anomalies and the left-right asymmetry in a specific dermatoglyphic characteristic of the palms, the atd angle. This composite measure possessed a linear relationship with a hand preference inventory and both linear and curvilinear relationships with a measure of relative hand skill. Study 2 replicated these results and extended them to a wider variety of physical left-right asymmetries. Three major implications of these results are discussed. First, variations in early fetal development may be important for individual variations in the neural substrate of handedness, leading to both left-handedness and extreme right-handedness. Second, as developmental instability likely results from polygenic homozygosity, the present results may be incompatible with single-gene theories of handedness. Third, the theoretical underpinnings of developmental instability offer a novel way to account for the association of left-handedness with some neurodevelopmental disorders.
\end{abstract}

Theories of handedness are generally of two sorts. One set (e.g., Corballis \& Morgan, 1978) posits a nearuniversal neural design leading to left-hemisphere language dominance and right-hand preference. In this view, deviations from the typical design (such as non-righthandedness) generally reflect social pressures or environmental insults such as anoxia and lateralized cortical damage. A second set proposes that variations in handedness reflect the expression of different neural designs due to genetic differences between individuals (Annett, 1985; McManus, 1985). Proponents of the former approach point to associations of handedness with birth stress and obstetric complications (Bakan, Dibb, \& Reed, 1973; Searleman, Porac, \& Coren, 1989). Proponents of the latter approach argue that acquired brain damage can account for only $5 \%$ or so of left-handedness (Bishop, 1990) and that family data suggest that genetic effects play a pervasive role in the determination of hand preference (e.g., Risch \& Pringle, 1985).

A unique perspective inspired by a well-established and diverse literature regarding developmental instability may provide an integrative framework for understanding the impact of both environmental factors and genetic predispositions on hand preference. Waddington (1957), Lerner (1954), and Thoday (1955) proposed that selection favors genomes resistant to or buffered from environmental or

\footnotetext{
We wish to thank Robert Thoma, Gloria Madrid, Cherry Lakins, and Eugene Tsinajinnie for their help with data collection. Correspondence may be addressed to either of the first two authors at the Department of Psychology, University of New Mexico, Albuquerque, NM 87131.
}

genetic perturbations that can cause an individual's developmental design to be expressed imprecisely. Infections, toxins, unfavorable mutations, or environmental conditions outside of the normal range encountered by a species are examples of factors that can potentially disrupt development. Genomes resistant to such influences are said to canalize development. A major canalizing genomic feature is widespread genetic heterozygosity. By conferring multiple molecular forms of gene products at a single locus, heterozygosity may increase the range of environments in which an individual may function adaptively, and thereby buffer an individual from perturbations. Through sexual recombination, however, genetic heterozygotes inevitably produce some offspring who are relatively homozygotic. Hence, any natural population in which genetic heterozygosity has been selected includes individuals who are relatively susceptible to environmental perturbations. When these individuals encounter such perturbations, developmental design may be expressed imprecisely.

Classic markers of developmental instability are fluctwating asymmetries, deviations from population-typical symmetry in bilateral characteristics (Palmer \& Strobeck, 1986; Parsons, 1990; Van Valen, 1962). Generally speaking, the left and right sides of a bilateral characteristic are regulated by the same genes. Population-atypical differences between the two sides thus result from imprecise expression of the developmental design for at least one of the two sides. Substantial evidence links fluctuating asymmetries with generalized homozygosity (Kat, 1982; Leary, Allendorf, \& Knudsen, 1975, 1983, 1984; Livshits \& Kobyliansky, 1991; Mitton \& Grant, 1984; 
Soule \& Couzin-Roudy, 1982). For example, protein homozygosity has been associated with greater left-right asymmetry in the size of pectoral fins of rainbow trout (Leary et al., 1975, 1983, 1984). Another criterion of developmental instability is slow growth rate. Slow growth rate (e.g., slow fetal development) has also been associated with protein homozygosity in a variety of species (Danzmann, Ferguson, Allendorf, \& Knudsen, 1986; Koehn \& Gaffney, 1984; Mitton \& Grant, 1984; Zouros, Romero-Dorey, \& Mallet, 1988; Zouros, Singh, \& Miles, 1980).

The speculation that deviations in cerebral lateralization revealed by non-right-handedness might result from developmental instability was first offered in a brief commentary by Van Valen (1978). He suggested that neural development is designed to result in moderate hemispheric asymmetry, with left-hemisphere dominance for language and hand preference. Early disruption of the developmental processes producing this design may lead to its imprecise or incomplete expression. Non-right-handers, then, may simply be those in whom certain developmental design features have been imprecisely expressed-that is, those pertaining to the neural underpinnings of handedness. More recently, Markow (1992b) has suggested that deviations from modal handedness in either directiontoward either left-handedness or extremely strong righthandedness-may result from developmental instability.

To date, only indirect evidence links markers of developmental instability-slow fetal development, developmental disruptions, or fluctuating asymmetries-to hand preference. Left-handers are overrepresented among preterm infants (Ross, Lipper, \& Auld, 1987) and infants with extremely low birth weights (O'Callaghan et al., 1987), and they may have lower APGAR scores at birth (Schwartz, 1990). In light of recent evidence for greater right-hand preference in thumb sucking at approximately 18 weeks gestational age (Hepper, Shahidullah, \& White, 1991), hand preferences probably predate these perinatal associations with handedness. Indeed, left- and righthanders may differ as early as the first trimester. Variations in hand preference relate to ridge and whorl patterns of the palms and fingers (Leche, 1933; Newman, 1934; Rife, 1955), features that are determined by the 10th week of gestation (Jantz, Fohl, \& Zahler, 1979). Interestingly, dermatoglyphic associations of non-righthandedness include greater absolute asymmetry between the hands (Rife, 1955) and relatively fewer palmar ridges, a manifestation of slowed development (Jantz et al., 1979). Hence, these investigations suggest a link between handedness and early developmental instability.

In Study 1, we attempted to assess links between handedness and developmental instability by measuring two markers of developmental instability. First, we examined associations between handedness and minor physical anomalies (MPAs). These features, first documented by Down (1866), are minor abnormalities due to deviations in early fetal development, as evidenced by their prevalence in a variety of disordered populations, such as
Down's Syndrome children (Down, 1866), schizophrenics (Gualtieri, Adams, Shen, \& Loiselle, 1982), autistics (Campbell, Geller, Small, Petti, \& Perris, 1978; Gualtieri et al., 1982; Steg \& Rapoport, 1975), hyperactive children (Gualtieri et al., 1982; Quinn \& Rapoport, 1974; Rapoport \& Quinn, 1975; Waldrop \& Halverson, 1971), dyslexics (Cummings, Flynn, \& Preus, 1982; Steg \& Rapoport, 1975; Von Hilsheimer \& Kurko, 1979), and children with behavior problems (Halverson \& Victor, 1976). The most popular assessment of MPAs, which was developed and standardized by Waldrop and Halverson (1971; Waldrop, Halverson, \& Shetterly, 1989), involves examination of 18 selected features of the head, hands, and feet. Some MPAs are considered to be outcomes of slowed development of given features in time-locked developmental sequences. For example, two MPAs are wide-spaced eyes and low ears. In the first trimester, the eyes gradually move toward each other and the ears migrate upward from the neck. Slow development during this period may produce widely spaced eyes and low ears in the adult. Other MPAs appear to result directly from disrupted development (e.g., malformed ears).

Second, we measured a specific fluctuating asymmetry, the atd angle difference. On each palm of most persons, three convergence points of ridge patterns (the $a, t$, and d triradii) form a $\mathbf{V}$-shape characterized by an angle between the two arms of the $\mathbf{V}$ (the maximum atd angle) (Penrose, 1954). Left-right asymmetry of the atd angle (the absolute difference between the atd angle of the two palms) is associated with developmental disorders such as cleft-palate syndrome and, hence, appears to be an indicator of developmental instability (Adams \& Niswander, 1970; Woolf \& Ganas, 1976). We correlated a composite measure of developmental instability based on these two assessments with self-reported hand preference and a commonly used measure of relative hand skill (Annett, 1985).

In light of Markow's (1992b) suggestion that any deviation from modal functional hemispheric asymmetries may result from developmental instability (such that both non-right-handers and unusually strong right-handers may show signs of developmental disruption), we also examined curvilinear relations of relative hand performance with indicators of developmental instability. Hand preference questionnaires are probably not sufficiently sensitive to differences among right-handers to be useful in revealing curvilinear relations (e.g., Annett, 1991).

\section{STUDY 1}

\section{Method}

Subjects. The subjects were 113 University of New Mexico undergraduate students (54 men and 59 women) who participated in exchange for course credit. Their mean age was 21.6 years $(S D=$ 6.44). When the study was announced in classrooms, non-righthanders were encouraged to participate.

Procedures. The subjects reported in groups of 1 to 4 . After reading and signing consent forms, they were administered several measures: 
The Annett Handedness Questionnaire (Annett, 1970): The subjects completed an abbreviated self-report measure of hand preference (omitting items on use of hammer and toothbrush) across 10 different tasks (e.g., writing, using scissors); each item was scored $0=$ right, $1=$ both equal, $2=$ left $(\alpha=.90)$.

The Annett peg-moving task (Annett, 1985): The subjects were timed while moving a series of 10 pegs from one row into another row of holes with either the right or the left hand. Relative hand performance was calculated as the average time taken for 5 righthanded trials minus the average time taken for 5 left-handed trials. High scores reflect left-handedness and low scores right-handedness (alpha coefficient of right-left differences for five trials $=.82$ ).

Minor Physical Anomalies Checklist (Waldrop \& Halverson, 1971; Waldrop et al., 1989): The subjects were examined for 18 different minor physical anomalies of the head (deviant head circumference, electric hair, multiple hair whorls), eyes (epicanthic folds, hypertelorism), ears (low ears, attached earlobes, malformed ears, asymmetrical ears, soft and pliable ears), mouth (steepled palate, tongue furrows, smooth-rough spots), hands (curved fifth finger, single transverse crease), and feet (webbed toes, third toe longer than second, large gap between first and second toes). Aggregation yielded a score of total MPAs.

atd Angle Asymmetry (Penrose, 1954): Handprints of subjects' right and left palms were taken (two from each hand), from which maximum atd angles were measured to the nearest $.5^{\circ}$. Under each finger, there is a convergence point of three sets of dermal ridges, forming a triradius. These triradii are labeled "a" (index finger) through " $d$ " (little finger). On the lower outer portion of the palm, approximately under the fourth finger, is a similar convergence point " $t$," such that an angle can be drawn from a to $t$ to $d$ (see Figures 1 and 9 in Penrose, 1954). atd asymmetry is the absolute difference between the atd angle for the two hands (averaged across the two prints) $(\alpha=.95)$. $^{.}$

To avoid experimenter bias, two experimenters assessed each subject. One experimenter administered Annett's peg-moving task. In a separate room and blind to the handedness measure, the second experimenter assessed MPAs. The atd angles were measured by a rater blind to the subjects' handedness scores. In addition, the subjects completed a series of brief personality measures and were photographed (measures not reported here). After completing all measures, the subjects were fully debriefed and thanked.

\section{Results}

For descriptive purposes only, subjects were classified into handedness groups on the basis of the Annett Handedness Questionnaire. Those scoring below 7 can be considered right-handers $(N=84,75.7 \%$ of the total); those scoring between 7 and 13 , ambidextrous $(N=9,8.1 \%)$; and those scoring greater than 13 , left-handers $(N=18$, $16.2 \%)$. Twenty-four subjects $(22 \%)$ used the left hand for writing. Two subjects did not complete the measure. The mean for the total sample on the handedness questionnaire was $5.32(S D=5.76)$. The mean relative difference between hands (right minus left) on the pegmoving task was $-.32 \sec (S D=.74)$. Hand preference and relative hand performance on the peg-moving task correlated $.72(p<.001)$.

To reduce the total number of statistical tests, we performed our main statistical analyses on a composite measure of MPAs and atd asymmetry. To construct this measure, we first converted total MPAs and the atd angle asymmetry measure into $z$ scores. These were then added to create a composite measure of developmental instability.
As predicted, hand preference significantly correlated with the developmental instability composite $(r=.50$, $p<.001$ ). Also as predicted, relative hand performance correlated with the composite $(r=.47, p<.001) .^{2}$

To examine the possibility of a curvilinear relationship between hand performance and developmental instability, we regressed developmental instability on relative hand performance and its quadratic term (hand performance squared). These analyses revealed a significant curvilinear (quadratic) effect, $[\beta=.33, t(84)=3.44, p<$ $.001 \mathrm{~J}$. The linear and curvilinear components of relative hand performance together accounted for $31 \%$ of the variance in the composite measure (see Table 1).

Figure 1 shows the relationship between relative hand performance and the developmental instability composite measure revealed by this analysis. As can be seen, both strong right-handers and non-right-handers had greater scores on the developmental instability composite. The minima of the function (the relative hand performance associated with lowest scores on the developmental instability composite) was at about the 18 th percentile on the relative hand performance measure. Additional analyses revealed that these relations were not significantly stronger for one sex or the other.

\section{Discussion}

As predicted, minor physical anomalies and a specific fluctuating asymmetry, the atd angle difference, corre-

Table 1

Hierarchical Regression Analyses: Predicting Developmental Instability Composite from Linear and Quadratic Components of Relative Hand Performance, Study 1

\begin{tabular}{ccccccc}
\hline Step & $R^{2}$ & $d f$ & Component & $\beta$ & $t$ & Significance of $t$ \\
\hline 1 & .22 & 85 & linear & .47 & 4.90 & $<.001$ \\
2 & .33 & 84 & linear & .58 & 6.03 & $<.001$ \\
& & & quadratic & .33 & 3.44 & $<.001$ \\
\hline
\end{tabular}

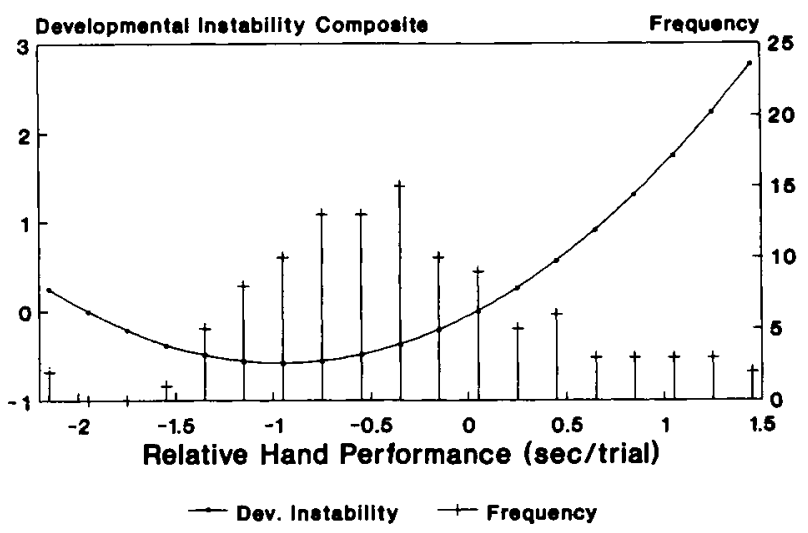

Figure 1. The curvilinear relationship between developmental instability and relative hand performance values and frequency $(N)$ of hand performance values: Study 1 . 
lated with measures of handedness. Moreover, both lefthanders and unusually strong right-handers possessed more of these indicators of developmental instability.

We conducted a second study designed to replicate and extend these findings. We once again measured MPAs and the atd angle differences. To assess a greater number and wider range of fluctuating asymmetries, however, we also measured both sides of seven morphometric bilateral characters: foot breadth, bimoleolar breadth, hand breadth, bistyloid breadth, biepicondylar breadth, ear length, and ear breadth. Livshits et al. (1988) have shown that asymmetries in these characters are greater in preterm infants, infants with cardiovascular and respiratory diseases, and infants whose mothers had infectious diseases during pregnancy, associations which suggest that these asymmetries are valid markers of developmental instability.

\section{STUDY 2}

\section{Method}

Subjects. The subjects were 121 University of New Mexico undergraduates ( 57 men and 64 women) who participated in exchange for course credit. Their mean age was 23.6 yrs. $(S D=$ 6.99).

Procedure. The procedure was identical to that in Study 1 , with one exception. In addition to assessing MPAs and the atd asymmetry, we also measured the two sides of the body at seven other discrete points: feet, ankles, hands, wrists, elbows, and ears (both length and breadth; see Livshits \& Kobyliansky, 1989, for details). Following Palmer and Strobeck's (1986) recommendations, we computed fluctuating asymmetries (FAs) on these structural features by computing the absolute difference in size across the two sides of the body and dividing this difference by the average of the two sides:

$$
\text { Individual } F A=\frac{|R-L|}{.5(R+L)}
$$

To compute a total FA measure, we $z$-scored the seven individual structural FAs and the atd asymmetry and then summed across all eight features. It should be noted that FAs do not typically intercorrelate with each other at the individual level, only at the population level (Soule, 1982).

As in Study 1, two experimenters assessed each subject. One administered Annett's (1985) peg-moving task. The other experimenter measured fluctuating asymmetries and assessed MPAs. Raters blind to the subjects' handedness scored the atd angles.

\section{Results}

On the basis of the same criteria as in Study 1, 104 (86.7\%) of our subjects could be classified as right-handed for descriptive purposes, $5(4.2 \%)$ as ambidextrous, and $11(9.2 \%)$ as left-handed. The mean for the total sample was $3.74(S D=4.68)$. Seventeen subjects $(14 \%)$ wrote with the left hand. The mean relative (right minus left) hand difference on the peg-moving task was $-.42(S D=$ .51). It should be noted that fewer non-right-handers were obtained in Study 2 than in Study 1. Correspondingly, the correlation between hand preference and relative hand performance was somewhat reduced $(r=.57, p<.001)$.

As in Study 1, we performed our main analyses on a composite measure of MPAs and FAs, which provided an overall measure of developmental instability. To compute this composite, we converted total MPAs and total FAs into $z$ scores and then summed them.

The results essentially replicated those of Study 1 . Both hand preference and relative hand performance significantly correlated with the developmental instability composite ( $r s=.41$ and .28 , respectively, $p s<.01$ ). Additional analyses regressing the composite measure on the linear and quadratic components of relative hand performance yielded a significant curvilinear relation $[\beta=.45$, $t(107)=3.28, p<.002]$. The linear and quadratic components of relative hand performance together accounted for $16 \%$ of the variance in the developmental instability composite (see Table 2). The results were not significantly moderated by sex.

Figure 2 illustrates the relation between relative hand performance and the composite measure. As in Study 1, both strong right-handers and left-handers in our sample tended to possess high scores on the developmental instability composite measure. The relative hand performance associated with lowest scores on the composite measure was at about the 27 th percentile.

To examine the associations of individual MPAs and FAs with handedness, we combined samples from both studies. Table 3 presents the linear (Pearson) correlations of individual MPAs and FAs with hand preference and hand performance. Also indicated are curvilinear relationships of each item with hand performance. It can be seen that the overall relationship of handedness to the develop-

Table 2

Hierarchical Regression Analyses: Predicting Developmental Instability Composite from Linear and Quadratic Components of Relative Hand Performance, Study 2

\begin{tabular}{ccccccc}
\hline Step & $R^{2}$ & $d f$ & Component & $\beta$ & $t$ & Significance of $t$ \\
\hline 1 & .08 & 108 & linear & .28 & 3.05 & .003 \\
2 & .16 & 107 & linear & .63 & 4.56 & $<.001$ \\
& & & quadratic & .45 & 3.28 & .001
\end{tabular}

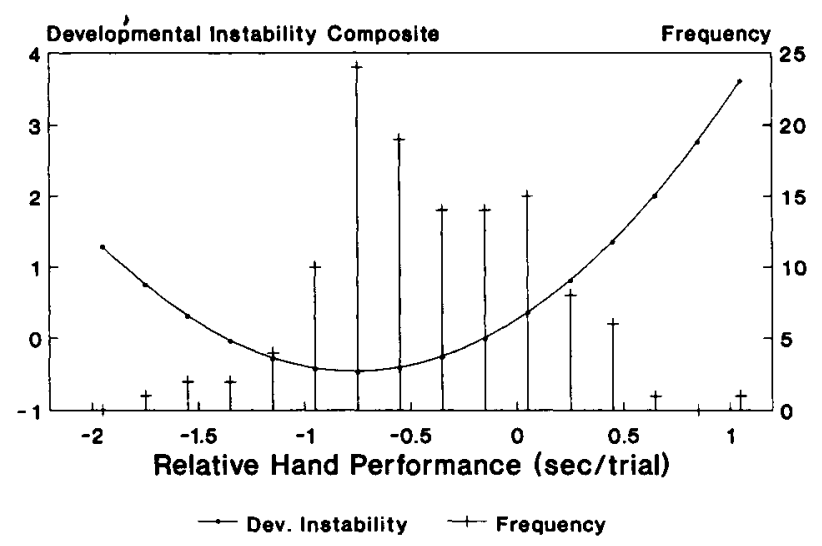

Figure 2. The curvilinear relationship between developmental instability and relative hand performance values and frequency $(N)$ of hand performance values: Study 2. 
Table 3

Correlations of Individual Minor Physical Anomalies (MPAs) and Fluctuating Asymmetries (FAs) with Hand Preference and Linear and Quadratic Components of Relative Hand Performance

\begin{tabular}{|c|c|c|c|}
\hline \multirow[b]{2}{*}{ Item } & \multirow[b]{2}{*}{$\begin{array}{l}\text { Hand } \\
\text { Preference }\end{array}$} & \multicolumn{2}{|c|}{ Hand Performance } \\
\hline & & $\begin{array}{c}\text { Linear } \\
\text { Component }\end{array}$ & $\begin{array}{l}\text { Quadratic } \\
\text { Component }\end{array}$ \\
\hline \multicolumn{4}{|c|}{ Minor Physical Anomalies } \\
\hline Electric hair & .20 & .13 & .13 \\
\hline Multiple hair whorls & .21 & .15 & .06 \\
\hline Abnormal head circumference & .05 & .00 & .10 \\
\hline Epicanthic folds & .08 & .15 & .04 \\
\hline Wide spaced eyes & .12 & .13 & -.02 \\
\hline Malformed ears & .09 & .03 & -.04 \\
\hline Low-seated ears & .10 & .06 & .02 \\
\hline Adherent ear lobes & .10 & .06 & .02 \\
\hline High palate & .11 & .09 & .00 \\
\hline Tongue furrows & .09 & .03 & -.05 \\
\hline Smooth or rough tongue & .12 & .08 & -.06 \\
\hline Curved fifth finger & .19 & .10 & -.02 \\
\hline Single palmar crease & -.01 & .15 & .00 \\
\hline Longer third toe & -.05 & -.03 & .04 \\
\hline Gap between first two toes & .20 & .05 & .04 \\
\hline
\end{tabular}

Fluctuating Asymmetries

\begin{tabular}{lrrr} 
atd angle & .16 & .15 & .29 \\
Foot width & .03 & .03 & .03 \\
Ankle width & .30 & .22 & .04 \\
Hand width & .05 & .08 & .13 \\
Wrist width & -.17 & .05 & -.11 \\
Elbow width & .08 & -.01 & .09 \\
Ear width & .08 & .07 & .11 \\
Ear length & .28 & .18 & .08 \\
\hline
\end{tabular}

Note-No subjects showed two particular MPAs, soft and pliable ears and partial syndactlia of the two middle toes. Critical values at $p<$ .05 : For MPAs and atd angle, $r=.14$; for other FAs, $r=.18$.

mental instability composite is not carried by a small subset of particular items. The percentages of items that correlated in the predicted direction with hand preference, hand performance, and the curvilinear component of hand performance were $87 \%$ ( 21 of 24$), 96 \%$ (23 of 24 ), and $75 \%$ (18 of 24$)$, respectively. ${ }^{3}$

\section{GENERAL DISCUSSION}

Individuals with relatively greater left-hand preference and skill show greater evidence of developmental instability, as indexed by a set of minor physical anomalies and specific fluctuating asymmetries. Importantly, extreme right-handers also show evidence of relatively greater developmental instability. These results have several implications for theories of individual variation in handedness and cerebral lateralization. First, they suggest that variations in patterns of early fetal development are important for variation in the neural substrates of handedness. Second, given the association of developmental instability with polygenic homozygosity, these results appear inconsistent with single-gene theories of variations in handedness. Finally, the theoretical perspective of de- velopmental instability offers a novel way to account for the association of non-right-handedness with a wide variety of neurodevelopmental disorders. We discuss each of these implications in greater detail below.

\section{The Importance of Early Fetal Development}

MPAs result from deviations in development during the first trimester of pregnancy (Waldrop \& Halverson, 1971; Waldrop et al., 1989). FAs, on the other hand, could possibly result from variability in growth rates over more substantial periods of time. But because FAs are evident at birth and are associated with perinatal complications such as low birth weight and prematurity (Livshits et al., 1988), variations in growth rates during prenatal development would appear to be important determinants of FAs.

The present results are quite consistent with those recently reported by Hepper et al. (1991). Ultrasound scans of fetuses revealed that of those observed to be sucking the thumb, $92 \%$ used the right hand, a figure remarkably close to the incidence of right-handedness reported in adult populations (e.g., $90 \%$ in a recent study of more than one million individuals; Gilbert \& Wysocki, 1992). The righthand bias was observed in fetuses between 15 and 21 weeks gestational age and did not appreciably change throughout the remainder of pregnancy. The neural substrate of handedness appears to be determined, or at least strongly influenced by, events occurring long before birth. Any observed association between measures of perinatal distress and left-handedness may thus reflect long-standing developmental fetal abnormalities, rather than a causal link between perinatal complications and handedness.

Unlike the environmental insults discussed by Bakan et al. (1973) and Satz (1972, 1973), the environmental perturbations that can cause developmental deviations are apparently pervasive. Although particularly prevalent in extreme environments, developmental instability is not uncommon in populations exposed to modal natural environments (e.g., Leary et al., 1983). In typical environments, infectious agents may be omnipresent, and, hence, so too may be sources of developmental disruption. As a result, genetic vulnerability may distinguish individuals with imprecise neural development better than environmental factors.

\section{Developmental Instability and \\ Atypical Handedness}

An intriguing aspect of our findings is the curvilinear relation between relative hand performance and markers of developmental instability (see Figures 1 and 2). These findings suggest that developmental instabilities may cause deviations from predominant patterns of functional lateralization in either direction, including extreme righthandedness and non-right-handedness. We propose that there is no variability in the direct genetic coding for the neurobiological substrate for handedness. Individuals vary only in the genes that determine how precisely the uni- 
versal design is expressed. Of course, in a small proportion of individuals, perinatal brain damage may also influence handedness.

In both Figures 1 and 2, the minima of the function relating developmental instability to relative hand performance falls slightly toward the left-handed side of the mean relative hand performance score. This suggests that developmental instability is more apt to lead to lefthandedness than to extreme right-handedness. The general asymmetry of the neural design toward lefthemisphere dominance may serve to limit additional deviations in this direction.

These results have important implications for attempts to relate variations in handedness to pathological conditions. Those using handedness questionnaires may underestimate the true degree of association, because of the insensitivity of such measures to extreme right-handedness. In this regard, it is interesting to consider the example of dyslexia. Though it has long been claimed that dyslexia is associated with left-handedness, supporting data from questionnaire studies are quite sparse (Bishop, 1990). Annett and Manning (1990) have recently shown that individuals at either extreme on a hand performance measure scored lower on a reading test than did those toward the middle of the distribution.

\section{Single-Gene Theories of Handedness}

Annett (1985) and McManus (1985) each propose single-gene models that share several features. Genes influence cerebral dominance and only secondarily affect hand preference. Right-hemisphere (and consequently lefthand) dominance is not directly coded for by genes. Rather, the genotype of left-handers codes for the absence of left-hemisphere dominance. Chance factors determine handedness in individuals with this genotype, so only $50 \%$ develop right-hemisphere dominance and left-handedness.

Two aspects of our data appear to be incompatible with these theories. First, developmental instability likely results from polygenic homozygosity (as well as, perhaps, other genomic features; Waddington, 1957), not a single gene. Second, the observed curvilinear relationship provides evidence that extreme right-handers and non-righthanders share an early development characterized by some degree of developmental instability. Neither single-gene theory would predict this effect.

There is another weakness in these single-gene theories. They do not provide a plausible account of the evolutionary basis of variation in handedness. Annett (1985) has been most explicit in her theorizing on this issue. On the basis of estimated gene frequencies, she has proposed that strong selection pressures favor individuals heterozygous at the single locus influencing cerebral dominance. Different cognitive liabilities are posited for individuals at either end of the continuum of relative hand preference. Deficits in phonological processing are more apt to be seen in those with relatively greater left-hand skill (Annett, 1992), whereas deficits in intelligence and mathematics are more frequent in those with relatively greater right- hand skill (Annett \& Manning, 1989). Heterozygotes, in the middle portion of the distribution, are said to be prone to neither of these difficulties, an advantage hypothesized to drive gene frequencies. There is little evidence, however, that variations in phonology, reading, mathematics, or intelligence are linearly related to fitness. If there were directional selection pressures for such skills, one would not expect to see significant population variability attributable to additive genetic variance (Fisher, 1959).

The nature of the heterozygote advantage proposed by Annett (1985) is different from that typically discussed in population biology, where heterozygote advantage is seen to result directly from the greater protein polymorphism of the heterozygote. Such polymorphism may allow more "back-up" capacity in multiple metabolic pathways (Markow, 1992a; Soule, 1982). Although there may well be unique patterns of cognitive skills associated with variations in lateralization, such differences between individuals are unlikely to be important selection factors.

\section{Neurodevelopmental Correlates of Handedness}

The theoretical underpinnings of developmental instability may offer some insight regarding the associations of handedness with a variety of developmental and other disorders. MPAs are prevalent in a variety of populations, including Down's Syndrome children, schizophrenics, autistics, hyperactive children, dyslexics, alcoholics, and children with behavior problems-all of them populations claimed to show an excess of non-right-handers (Boucher, 1977; Colby \& Parkinson, 1977; Lishman \& McMeekan, 1976; Nasrallah, Keelor, \& McCalley-Winters, 1983; Ross et al., 1987). Fluctuating asymmetries are also relatively common in schizophrenics (Markow \& Gottesman, 1989; Markow \& Wandler, 1986), as well as preterm and low birth-weight infants (Livshits et al., 1988)-other populations that may show an excess of non-right-handers (O'Callaghan et al., 1987).

It is possible that each of these disorders is, in part, produced by developmental instability. The neurobiological abnormalities underlying these conditions are likely quite diverse, but the factors leading to developmental abnormalities may be quite similar.

\section{Additional Future Directions}

These findings raise a number of additional conceptual issues. What specific neural substrates are affected by developmental instabilities to cause non-right-handedness? Are other functional cerebral asymmetries, such as those for language skills, influenced in similar ways? Are developmental instabilities associated with hormonal deviations (such as those specified by Geschwind \& Galaburda, 1987) that play some role in the development of functional laterality? Although developmental instabilities are presumed to be predisposed by homozygosity at many genetic loci, are any specific loci particularly important? While genetic factors may predispose one to developmental disruptions, environmental perturbations such as infection, toxins, and stress-induced deviant intrauter- 
ine milieu are presumably the proximate causes of developmental instability. What are the relative roles of these environmental perturbations? Understanding the nature and mechanisms of developmental instability may illuminate these and other questions about the origins of neurodevelopmental variation.

\section{REFERENCES}

Adams, M. S., \& Niswander, J. D. (1970). Developmental noise and a cohgenital malformation. Genetic Research, 10G, 313-317.

ANNETT, M. (1970). A classification of hand preference by association analysis. British Journal of Psychology, 61, 303-321.

ANNETT, M. (1985). Left, right, hand, and brain: The right shift theory. Hillsdale, NJ: Eribaum.

ANNETT, M. (1991). Annotation: Laterality and cerebral dominance. Journal of Childhood Psychology \& Psychiatry, 32, 219-237.

ANNETT, M. (1992). Phonological processing and right minus left hand skill. Quarterly Journal of Experimental Psychology, 44A, 33-46.

ANNett, M., MANning, M. (1989). The disadvantages of dextrality for intelligence. British Journal of Psychology, 80, 213-226.

ANNETT, M., \& MANNING, M. (1990). Reading and a balanced polymorphism for laterality and ability. Journal of Childhood Psychology \& Psychiatry, 31, 511-529.

Bakan, P., Dibb, G., \& ReEd, P. (1973). Handedness and birth stress. Neuropsychologia, 11, 363-366.

Bisнop, D. V. M. (1990). Handedness and developmental disorders. Oxford: Blackwell Scientific Press.

BOUCHER, J. (1977). Hand preference in autistic children and their parents. Journal of Autism \& Childhood Schizophrenia, 7, 177-187.

Campbell, M., Geller, B., Small, A. M., Petti, T. A., \& Perris, S. H. (1978). Minor physical anomalies in young psychotic children. American Journal of Psychiatry, 135, 573-575.

Colby, K. M., \& Parkinson, C. (1977). Handedness in autistic children. Joumal of Autism \& Childhood Schizophrenia, 7, 3-9.

Corballis, M. C., Morgan, M. J. (1978). On the biological basis of human laterality: I. Evidence for a maturational left-right gradient. Behavioral \& Brain Sciences, 2, 261-269.

Cummings, C., Flynn, D., \& Preus, M. (1982). Increased morphological variants in children with learning disabilities. Journal of Autism \& Childhood Schizophrenia, 12, 373-383.

Danzmann, R. G., Ferguson, M. M., Allendorf, F. W., KnudSEN, K. L. (1986). Heterozygosity and developmental rate in a strain of rainbow trout (Salmo gairdneri). Evolution, 40, 86-93.

Down, J. L. H. (1866). Observations on an ethnic classification of idiots. London Hospital \& Lecture Reports, 3, 259-262.

FiShER, R. A. (1959). The genetical theory of natural selection. New York: Dover.

Geschwind, N. W., \&alaburda, A. M. (1987). Cerebral lateralization: Biological mechanisms, associations, and pathology. Cambridge, MA: MIT Press.

GilberT, A. N., \& WYsOckI, C. J. (1992). Hand preference and age in the United States. Neuropsychologia, 30, 601-608.

Gualtieri, C. T., Adams, A., Shen, C. D., \&oiselle, D. (1982). Minor physical anomalies in alcoholic and schizophrenic adults and hyperactive and autistic children. American Journal of Psychiatry, 139, 640-643.

Halverson, C. F., \& Victor, J. B. (1976). Minor physical anomalies and problem behavior in elementary school children. Child Development, 47, 281-285.

Hepper, P. G., Shahidullah, S., \& White, R. (1991). Handedness in the human fetus. Neuropsychologia, 28, $1107-1111$.

JANTZ, R. L., Fohl, F. K., \& ZAHLER, J. W. (1979). Finger ridgecounts and handedness. Human Biology, 51, 91-99.

KAT, P. W. (1982). The relationship between heterozygosity for enzyme loci and developmental homeostasis in peripheral populations of aquatic bivalves (Unenidice). American Naturalist, 119, 824-832.

KoEHN, R. K., \&AFFNEY, P. M. (1984). Genetic heterozygosity and growth rate in Mytilus edulis. Marine Biology, 82, 1-7.

Leary, R. F., Allendorf, F. W., \& KNudSEN, K. L. (1975). In- heritance of meristic variation and the evolution of developmental instability in rainbow trout. Evolution, 39, 308-314.

Leary, R. F., Allendorf, F. W., KNudsen, K. L. (1983). Developmental instability and enzyme heterozygosity in rainbow trout. $\mathrm{Na}$ ture, 301, 71-72.

Leary, R. F., Allendorf, F. W., \& KnUdSEN, K. L. (1984). Superior developmental stability of heterozygotes at enzyme loci in salmonid fishes. American Naturalist, 124, 540-551.

LECHE, S. (1933). Handedness and bimanual dermatoglyphic differences. American Journal of Anatomy, 53, 1-53.

LERNER, I. M. (1954). Genetic homeostasis. New York: Wiley.

Lishman, W. A., \& Memekan, E. R. L. (1976). Hand preference patterns in psychiatric patients. British Joumal of Psychiatry, 129. 158-166.

Livshits, G., Davadi, L., Kobyliansky, E., Ben-Amital, D. LEVY, Y., MERLOB, P. (1988). Decreased developmental stability as assessed by fluctuating asymmetry of morphometric traits in preterm infants. American Journal of Human Genetics, 29, 793-805.

Livshits, G., Kobyliansky, E. (1989). Study of genetic variance in the fluctuating asymmetry of anthropomorphic traits. Annals of $\mathrm{Hu}$ man Biology, 16, 121-129.

Livshits, G., KoByLIANSKY, E. (1991). Fluctuating asymmetry as a possible measure of developmental homeostasis in humans: A review. Human Biology, 63, 441-446.

MArkow, T. A. (1992a). Genetics and developmental stability: An integrative conjecture on etiology and neurobiology of schizophrenia. Psychological Medicine, 22, 295-305.

MARKow, T. A. (1992b). Human handedness and the concept of developmental instability. Genetica, 87, 87-94.

MARKOW, T. A., \& GotTeSmaN, I. I. (1989). Fluctuating dermatoglyphic asymmetry in psychotic twins. Psychiatry Research, 29, 37-43.

MARKOW, T. A., \& W ANDLER, K. (1986). Fluctuating asymmetry and the genetics of liability to schizophrenia. Psychiatry Research, 19, 323-328.

MCMANUS, I. C. (1985). Handedness, language dominance, and aphasia A genetic model. Psychological Medicine (Monograph Suppl. 8), Cambridge: Cambridge University Press.

Mitton, J. B., Grant, M. C. (1984). Associations among protein heterozygosity, growth rate, and developmental homeostasis. Annual Review of Ecology \& Systematics, 15, 479-499.

Nasrallah, N. A., Keelor, K., McCalley-Winters, M. (1983). Laterality shift in alcoholic males. Biological Psychiatry, 18, 1056-1067.

NEWMaN, H. H. (1934). Dermatoglyphics and the problem of handedness. American Journal of Anatomy, 55, 277-322.

O'Callaghan, M. J., Tudehope, D. I., Dugdale, A. E., MoHAY, H., BURNS, Y., COOK, F. (1987). Handedness in children with birthweights below $1000 \mathrm{~g}$. Lancet, 7, 1155.

PAlmer, A. R., \& Strobeck, C. (1986). Fluctuating asymmetry: Measurement, analysis, and patterns. Annual Review of Ecology \& Systematics, 17, 391-421.

PArsons, P. A. (1990). Fluctuating asymmetry: An epigenetic measure of stress. Biological Review, 65, 131-145.

Penrose, L. S. (1954). The distal triradius $t$ on the hands of parents and sibs of mongol imbeciles. Annals of Human Genetics, 19, 10-38.

QuinN, P. O., \& RAPOPORT, J. L. (1974). Minor physical anomalies and neurologic status in hyperactive boys. Pediatrics, 53, 742-747.

RAPOPORT, J. L., \& QuinN, P. O. (1975). Minor physical anomalies and early developmental deviation: A major subgroup of hyperactive children. International Journal of Mental Health, 4, 29-44.

RIFE, D. C. (1955). Hand prints and handedness. American Journal of Human Genetics, 28, 41-48.

RISCH, N., \& PRINGLE, G. (1985). Segregation analysis of human hand preference. Behavior Genetics, 15, 385-400.

Ross, G., LIPPER, E. G., \& AULD, P. A. M. (1987). Hand preference of four-year-old children: Its relationship to premature birth and neurodevelopmental outcome. Developmental Medicine \& Child Neurology, 29, 615-622.

SATz, P. (1972). Pathological left-handedness: An explanatory model. Cortex, 8, 121-135.

SATZ, P. (1973). Left-handedness and early brain insult: An explanation. Neuropsychologia, 11, 115-117. 
SchWARTZ, M. (1990). Left-handedness and perinatal complications. In S. Coren (Ed.), Left-handedness: Behavioral implications and anomalies (pp. 75-98). New York: Elsevier.

Searleman, A., Porac, C., \& Coren, S. (1989). Relationship between birth order, birth stress, and lateral preferences: A critical review. Psychological Bulletin, 105, 397-408.

Smouse, P. T., Long, J. C., \& Sokal, R. R. (1986). Multiple regression and correlation extensions of the Mantel test of matrix correspondence. Systematics \& Zoology, 35, 627-632.

Soule, M. E. (1982). Allomeric variation: 1 . The theory and some consequences. American Naturalist, 120, 751-764.

Soule, M. E., \& CouziN-Roudy, J. (1982). Allomeric variation. 2. Developmental instability of extreme phenotypes. American Naturalist, 120, 765-786.

STEG, J. P., \& RAPOPORT, J. L. (1975). Minor physical anomalies in normal, neurotic, learning disabled, and severely disturbed children. Journal of Autism \& Childhood Schizophrenia, 5, 299-307.

ThoDaY, J. M. (1955). Balance, heterozygosity, and developmental stability. Cold Spring Harbor Symposium of Quantitative Biology, 20, 318-326.

VAN VALEN, L. (1962). A study of fluctuating asymmetry, Evolution, $16,125-142$.

VAN VALEN, L. (1978). The control of handedness. Behavioral \& Brain Sciences, 2, 320.

Von Hilsheimer, E., \& Kurko, J. (1979). Minor physical anomalies in exceptional children. Joumal of Learning Disabilities, 12, 462-469.

WADDINGTON, C. H. (1957). The strategy of the genes. New York: Macmillan.

WALDRoP, M. F., \& HALVERSON, C. F. (1971). Minor physical anomalies and hyperactive behavior in young children. In J. Hellmuth (Ed.), Exceptional infant: Studies in abnormality 2 (pp. 343-380). New York: Brunner, Mazel.
Waldrop, M. F., Halverson, C. F., \&hetterly, K. (1989). Manual for assessing minor physical anomalies (1989 revision). Unpublished manuscript, University of Georgia.

Woolf, C. M., \& GANAS, A. D. (1976). Congenital cleft lip and fluctuating dermatoglyphic asymmetry. American Journal of Human Genetics, 28, 400-403.

Zouros, E., Romero-Dorey, M., \& MAllet, A. L. (1988). Heterozygosity and growth in marine bivalves: Further data and possible explanation. Evolution, 42, 1332-1341.

Zouros, E., Singh, S. M., \& Miles, H. E. (1980). Growth rate in oysters: An overdominant phenotype and its possible explanation. Evolution, 34, 856-867.

\section{NOTES}

1. The atd angle asymmetry was not correlated with total atd size and, hence, we did not standardize asymmetry against size (Palmer \& Strobeck, 1986).

2. Because the developmental instability composite was positively skewed, we also performed randomization tests (based on 5,000 randomizations) to determine appropriate $p$ values for correlations involving this composite (see Smouse, Long, \& Sokal, 1986). The results were nearly identical to those reported in the text.

3. We also examined relations of hand preference and the linear and curvilinear components of relative hand performance with total MPAs and FAs separately within the combined sample. For no relation did one indicator significantly outperform the other.

(Manuscript received September 29, 1992; revision accepted for publication January 4,1993 .) 